\title{
Shrinkage Effect of Vacuum Casting Process Parameters using Taguchi Method
}

\author{
Mohd Nazri Bin Ahmad ${ }^{1,2 *}$, Nurul Ain Binti Maidin', Mohd Hidayat Bin Ab \\ Rahman $^{1,2}$, Mohd Hairizal Bin Osman ${ }^{1,2}$, Mohammad Khalid Bin Wahid ${ }^{1,2}$, \\ Mohamad Faris Bin Mohd Basir ${ }^{1}$
}

${ }^{1}$ Faculty of Engineering Technology, Universiti Teknikal Malaysia Melaka, Hang Tuah Jaya, 76100 Durian Tunggal, Melaka, MALAYSIA

${ }^{2}$ Advanced Manufacturing Centre on Energy, Universiti Teknikal Malaysia Melaka, Hang Tuah Jaya, 76100 Durian Tunggal, Melaka, MALAYSIA

*Corresponding Author

DOI: https://doi.org/10.30880/ijie.2019.11.03.026

Received 7 August 2019; Accepted 19 August 2019, Available online 31 August 2019

\begin{abstract}
This paper investigates the optimization of vacuum casting process by using Taguchi method. Vacuum casting process is a one of the method in Rapid Tooling Technology. The parts produced by vacuum casting process has it accuracy varies with the changes of the process parameters of the machine such as resin temperature, vacuum pressure time, mould temperature and some others. In order to optimize 3 parameters which are resin temperature, mould temperature and vacuum pressure time, the L'9 orthogonal array was used. From the results, it shows that the optimum parameters that may improve the shrinkage effect are resin temperature $\left(30{ }^{\circ} \mathrm{C}\right)$, mould temperature $\left(60^{\circ} \mathrm{C}\right)$ and vacuum pressure time $(5 \mathrm{~min}$.). The shrinkage values between default and optimum parameter are $0.159 \mathrm{~mm}$ and $0.336 \mathrm{~mm}$ respectively. Thus, the improvement on shrinkage effect was 52.4 percent. The study demonstrates that the better dimensional accuracy of vacuum casting process can be optimized using Taguchi Method.
\end{abstract}

Keywords: Taguchi method, vacuum casting, shrinkage, S/N ratio

\section{Introduction}

According to Radu and Fratila [1], vacuum casting is a modern technique that allows the manufacturing of pieces in small batches and individual fabrication at minimum price and shorter time. This technique aids to build intricate prototype parts with similar form details and surface quality of the duplicate master model. Jijociya et al. [2] reports the vacuum casting system can be divided into two which are embodies of vacuum chamber and heat chambers. Vacuum chamber enable for producing silicon rubber moulds and resin free of air bubbles formed during mixing. Compared accuracy of wax patterns created by hard tool (polyurethane mold) and soft tool (RTV mold). They found the injection pressure and holding time only have a slight effect on the accuracy of wax patterns and the only parameter that has an effect on the dimensional accuracy is the injection temperature [3]. Chua et al. [4] reports vacuum casting as one of the most flexible form of rapid prototyping and tooling for consumer products. Besides it is simpler to be applied and inexpensive tools and materials, vacuum casting increases the potential of silicone rubber mould in the batch production of functional prototype.

Osman et al. [5] has carried out a research to determine the optimization parameter for hole diameter accuracy in dry drilling process of AISI D2 Tool Steel using Taguchi method. In recent years, the rapid growth of interest in the 
Taguchi method has led to numerous applications of the method in a world-wide range of industries and nations [6]. Taguchi Parameter Design is a powerful and efficient method for optimizing the process, of diesel engine working on biodiesel using Taguchi method [7]. Furthermore, Taguchi's design of experiment method and analysis of variance (ANOVA) were applied in order to find optimum operating parameters giving the best engine performance and exhaust emissions with a minimum number of the engine tests in a spark ignition (SI) engine fueled with pure gasoline, ethanol and methanol [8]. Shrinkage behavior of a plastic plays a critical role in determining the final dimensions of an injection- molded part. It is well known that process conditions affect many properties of plastic parts, including shrinkage [9].

The aim of this study is optimizing vacuum casting parameter by Taguchi method.

\section{Research Methodology}

In this study, Taguchi method was used in optimizing vacuum casting parameter. The procedure for Taguchi analysis as shown in Fig. 1. The step of this study starts by determination of parameters of vacuum casting process. There are three parameters to analyze which are resin temperature, mould temperature and vacuum pressure time. Then select the control factor and level and create table of parameters. After that the experiments were conducted as per orthogonal array. The analysis of SN Ration and Means had been implemented and end of the methods by prediction of shrinkage value.

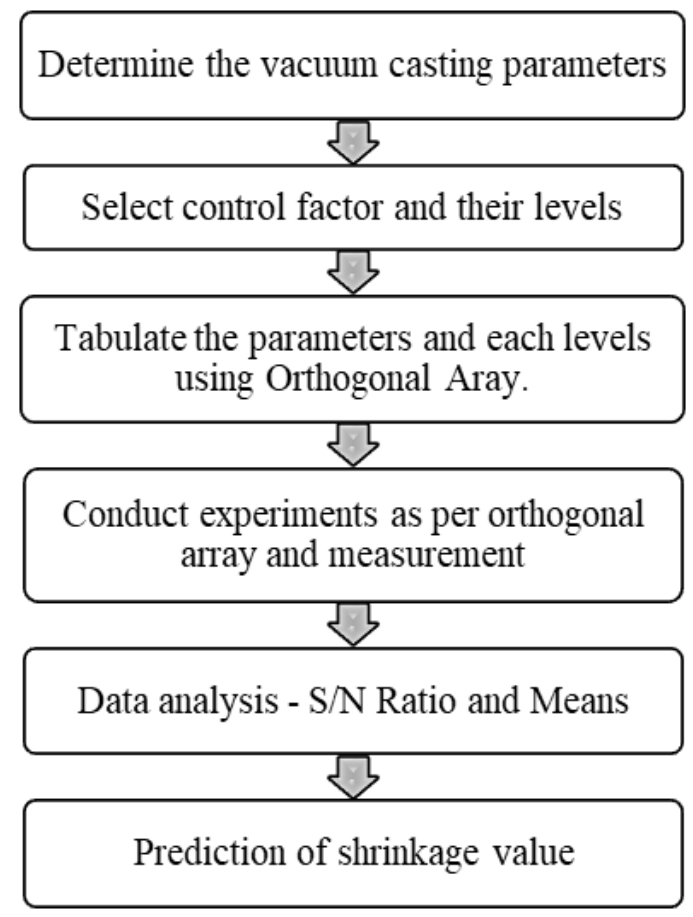

Fig. 1 - Procedure of Taguchi approach.

Three factors with three levels for each were considered. The experiments were conducted by implementing L-9 orthogonal array. Table 1 shows L-9 orthogonal array with 3 parameters which are resin temperature $\left({ }^{\circ} \mathrm{C}\right)$, mould temperature $\left({ }^{\circ} \mathrm{C}\right)$ and vacuum pressure time $(\mathrm{min})$.

Table 1 - Factors and their levels.

\begin{tabular}{ccccc}
\hline Serial & Factor & \multicolumn{3}{c}{ Levels } \\
\cline { 3 - 5 } & & 1 & 2 & 3 \\
\hline A & Resin temp. $\left({ }^{\circ} \mathrm{C}\right)$ & 20 & 25 & 30 \\
B & Mould Temp. $\left({ }^{\circ} \mathrm{C}\right)$ & 60 & 70 & 80 \\
C & Vacuum Time $(\min )$ & 5 & 10 & 15 \\
\hline
\end{tabular}

The experiment runs for 9 specimens and measure 6 section as shown in Fig. 2. Computer Measuring Machine 
(CMM) was used to record the data. Dimension at Section B was assigned as major section. Each dimension was measured three times and the average is considered. The value of shrinkage is calculated by using the Equation (1).

$$
\text { Shrinkage value }=L c-L m
$$

where $L c$ is the original dimension of CAD model and $L m$ is the measured dimension.

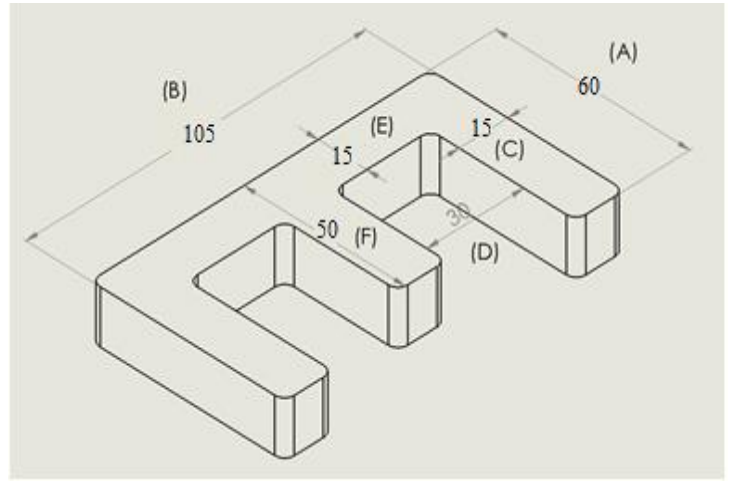

Fig. 2 - Vacuum casting specimens with six sections to be measured.

Minitab software has been used in the analysis of the data. The values of Signal to Noise Ratio (S/N Ratio) and means were obtained throughout the analysis. The use of 'smaller is better' equation in the signal to ratio, the graphs of main effects for signal to noise ratios and means are plotted. For smaller is better (S/N Ratio) was calculated based on Equation 2.

$$
\mathrm{S} / \mathrm{N}=-10 * \log \left(\Sigma\left(\mathrm{Y}^{2}\right) / \mathrm{n}\right)
$$

where, $Y$ is responses for the given factor level combination and $n$ is number of responses in the factor level combination.

\section{Results and Discussion}

\subsection{Experimental specimens and percentage error}

The 9 experiments of vacuum casting process have been conducted. The result of casting process by using PU resin types Axson PX223 as shown in Fig. 3 specimens.

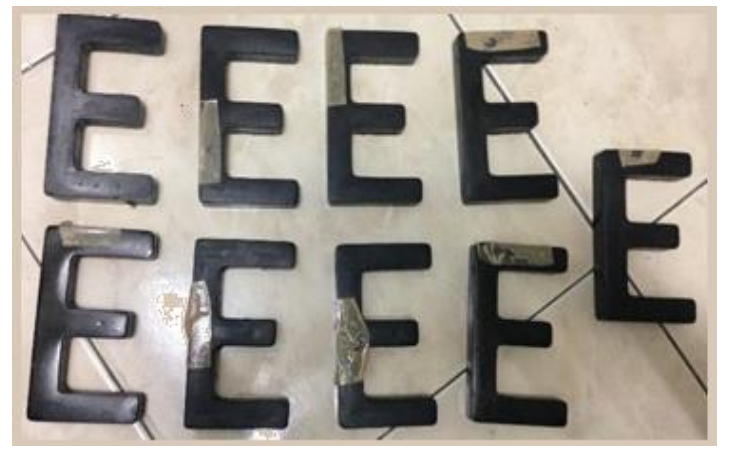

Fig. 3 - The 9 Specimens of vacuum casting parts.

Refer to Fig. 4, the graph shows the section $\mathrm{E}$ is the highest percentage of error. The percentage error for section $\mathrm{E}$ and $\mathrm{C}$ were $4.11 \%$ and $3.54 \%$. While, the section $\mathrm{D}$ and $\mathrm{F}$ error were $2.79 \%$ and $1.5 \%$. Meanwhile, section $\mathrm{A}$ is the second lowest of percentage of error with an average of 1.25. Lastly, section B has the lowest percentage of error $(0.21 \%)$ among others. Thus, section B was selected to be analyzed because it has the smallest percentage of the error. 


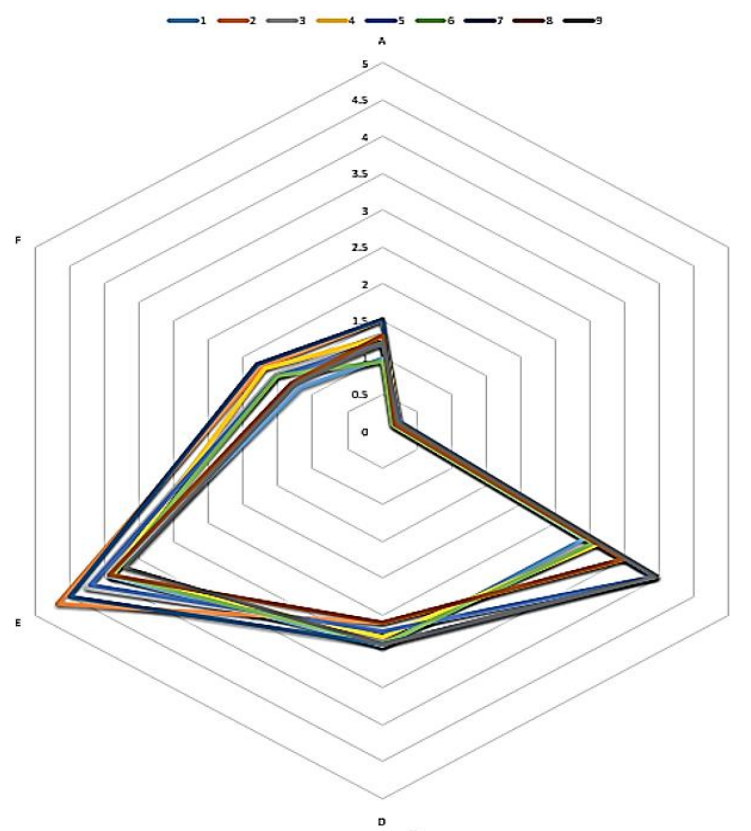

Fig. 4 - Percentage of error

The values of design experiment L-9 and section B shrinkage value has been tabulated in Table 2 . The measurement for shrinkage value was done by CMM to get accurate result.

Table 2 - L-9 Experiment and section B shrinkage results.

\begin{tabular}{ccccc}
\hline Run & $\begin{array}{c}\text { Resin } \\
\text { Temp } \\
\left({ }^{\circ} \mathbf{C}\right)\end{array}$ & $\begin{array}{c}\text { Mould } \\
\text { Temp. } \\
\left({ }^{\circ} \mathbf{C}\right)\end{array}$ & $\begin{array}{c}\text { Vacuum } \\
\text { Time } \\
(\mathbf{m i n})\end{array}$ & $\begin{array}{c}\text { Shrinkage } \\
\text { Value } \\
(\mathbf{m m})\end{array}$ \\
\hline 1 & 20 & 60 & 5 & 0.170105 \\
2 & 20 & 70 & 10 & 0.234580 \\
3 & 20 & 80 & 15 & 0.257925 \\
4 & 25 & 60 & 10 & 0.281740 \\
5 & 25 & 70 & 15 & 0.266970 \\
6 & 25 & 80 & 5 & 0.162320 \\
7 & 30 & 60 & 15 & 0.201785 \\
8 & 30 & 70 & 5 & 0.191465 \\
9 & 30 & 80 & 10 & 0.258070 \\
\hline
\end{tabular}

\subsection{Signal to noise ratio and mean}

The main effect plot for SN ratios and mean are shown in Fig. 5 and Fig. 6. In the SN ratio graph, the optimum parameter is observed by the highest level plotted. This is because the highest value of SN ratio means it has lower effect of noise factor. Based on the Section B main effect plot for $\mathrm{S} / \mathrm{N}$ ratios, the highest point plotted for resin temperature is at level $3\left(30^{\circ} \mathrm{C}\right)$. For mould temperature, the highest point is at level $1\left(60^{\circ} \mathrm{C}\right)$. Meanwhile for vacuum pressure time, the highest point is at level 1 ( $5 \mathrm{~min})$.

Mitra et al. [9] reports the main effect is a value which shows the extent of influence of a factor on the response. Hence, the combination for optimum parameter condition is $\mathrm{A} 3 \mathrm{~B} 1 \mathrm{C} 1\left(30^{\circ} \mathrm{C}, 60^{\circ} \mathrm{C}, 5 \mathrm{~min}\right)$ that will give the optimum shrinkage value for section $\mathrm{B}$ dimension. 


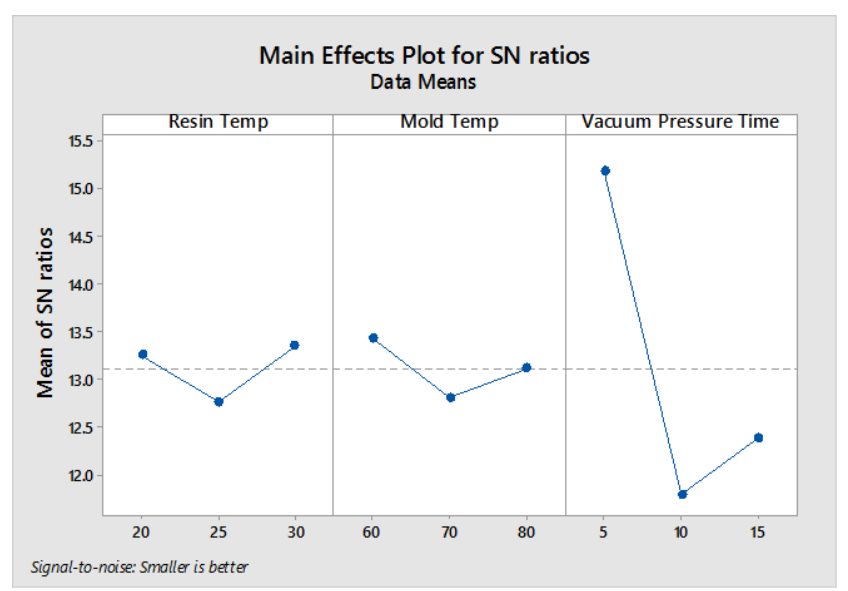

Fig. 5 - Section $B$ the main effects plot for $\mathrm{SN}$ ratios.

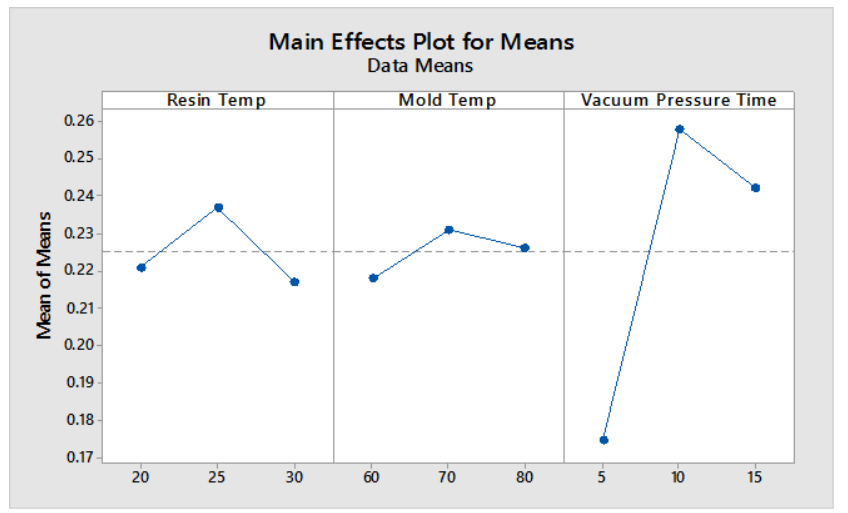

Fig.6 - Section B the main effect plot for means.

Table 3 and 4 show the response table for signal to noise ratio and means. The values of Delta are the difference between maximum and minimum average of $\mathrm{SN}$ ratio for the factor.

Table 3 - Section $B$ response table for SN ratios.

\begin{tabular}{cccc}
\hline Level & $\begin{array}{c}\text { Resin } \\
\text { Temperature }\end{array}$ & $\begin{array}{c}\text { Mould } \\
\text { Temparature }\end{array}$ & $\begin{array}{c}\text { Vacuum } \\
\text { Time }\end{array}$ \\
\hline 1 & 13.25 & 13.43 & 15.18 \\
2 & 12.76 & 12.81 & 11.79 \\
3 & 13.34 & 13.11 & 12.38 \\
Delta & 0.59 & 0.62 & 3.39 \\
Rank & 3 & 2 & 1 \\
& & &
\end{tabular}

Table 4 - Section B response table for means.

\begin{tabular}{cccc}
\hline Level & $\begin{array}{c}\text { Resin } \\
\text { Temperature }\end{array}$ & $\begin{array}{c}\text { Mould } \\
\text { Temparature }\end{array}$ & $\begin{array}{c}\text { Vacuum } \\
\text { Time }\end{array}$ \\
\hline 1 & 0.2179 & 0.2209 & 0.1746 \\
2 & 0.2310 & 0.2370 & 0.2581 \\
3 & 0.2261 & 0.2171 & 0.2422 \\
Delta & 0.0131 & 0.0199 & 0.0835 \\
Rank & 3 & 2 & 1 \\
\hline
\end{tabular}




\subsection{Predicted values and shrinkage comparison}

The analysis has implemented the combination of optimum parameter condition. Thus, the predicted value for shrinkage effect can be calculated. The factors such as resin temperature $\left(30^{\circ} \mathrm{C}\right)$, mould temperature $\left(60^{\circ} \mathrm{C}\right)$ and vacuum pressure time $(5 \mathrm{~min})$ are selected in the feature of 'Predict Taguchi Result'. So, the predicted shrinkage value by using the optimize parameter condition is $0.159 \mathrm{~mm}$ as in Fig. 7.

\begin{tabular}{|lrr|}
\hline \multicolumn{2}{|c|}{ Predicted values } \\
Mean \\
0.159622 \\
\multicolumn{4}{|c}{} \\
\multicolumn{4}{|c}{ Factor levels for predictions } \\
\multicolumn{4}{|c}{ Vacuum } \\
Resin & Mold & Pressure \\
Temp & Temp & Time \\
30 & 60 & 5 \\
& & \\
\hline
\end{tabular}

Fig. 7 - Predicted value using the optimize parameter

Fig. 8 shows the shrinkage values between default and optimum parameter. The optimized parameter condition is $0.159 \mathrm{~mm}$ and default is $0.336 \mathrm{~mm}$. That means the improvement of shrinkage effect is 52.4 percent.

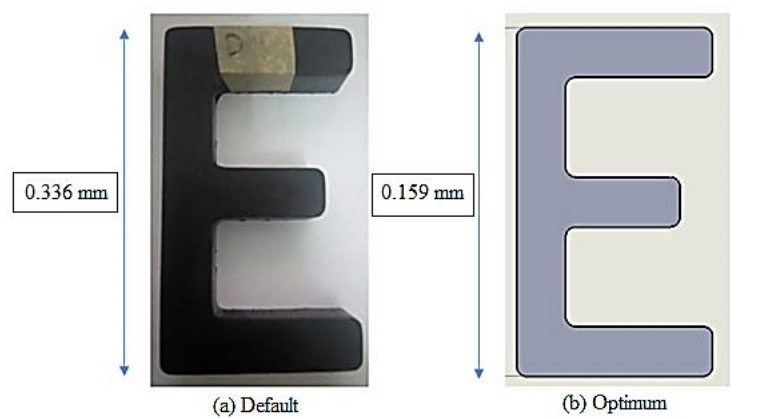

Fig. 8 - Shrinkage between default and optimum parameter

\section{Conclusion}

In conclusion, the optimum parameters condition for vacuum casting process are $30^{\circ} \mathrm{C}$ for resin temperature, $60^{\circ} \mathrm{C}$ for mould temperature and $5 \mathrm{~min}$ for vacuum pressure time. Vacuum pressure time contributes the most significant effect compare to the mould and resin temperature on the dimension accuracy of the part. The shrinkage values between default and optimum parameter are $0.159 \mathrm{~mm}$ and $0.336 \mathrm{~mm}$ respectively. Thus, the improvement on shrinkage effect was 52.4 percent.

\section{Acknowledgement}

The authors wish to thank Universiti Teknikal Malaysia Melaka (UTeM) for supporting this research (PJP/2015/FTK (11A)/S01416).

\section{References}

[1] Radu, S. A., \& Fratila, D. F. (2012). Simulation and experimental research on the vacuum casting of non-metallic complex parts using flexible molds. Proceedings of The Romanian Academy Series A-Mathematics Physics Technical Sciences Information Science, 13(4), 343-350.

[2] Jijotiya, D., Verma, Dr. P. L, Jain, P. S, Bajpai, Dr. L., and Manoria, P. A. (2013). Efficient Rapid Prototyping Mechanism Using Vacuum Casting (VC) Process. Certified Journal, 3 (6).

[3] Yarlagadda, P. K., \& Hock, T. S. (2003). Statistical analysis on accuracy of wax patterns used in investment casting process. Journal of materials processing technology, 138(1-3), 75-81. 
[4] Chua, C. K., Leong, K. F., \& Lim, C. S. (2010). Rapid prototyping: principles and applications. World Scientific Publishing Company.

[5] Osman, M. H., Hadzley, M., Tamin, N. F., Mohamad, N. J., Wahid, M. K., Ahmad, M. N., ... \& Ab Rahman, M. H. (2017). Optimization of drilling parameters in diameter accuracy on dry drilling process of AISI D2 tool steel. Proceedings of Mechanical Engineering Research Day 2017, 2017, 105-106.

[6] Brendell, A., Disney, J., \& Pridmore, W. A. (1989). Taguchi Methods: Applications in World Industry UK.

[7] Bharat, K. S., Mukund, S. A., Ramrao, T. B., Kadam, S. S. (2018). Analysis and optimization of diesel engine working on biodiesel using taguchi method. International Journal of Current Trends in Science and Technology, 8 (1), 72-75.

[8] Balki, M. K., Sayin, C., \& Sarıkaya, M. (2016). Optimization of the operating parameters based on Taguchi method in an SI engine used pure gasoline, ethanol and methanol. Fuel, 180, 630-637.

[9] Chang, T. C., \& Faison III, E. (2001). Shrinkage behavior and optimization of injection molded parts studied by the Taguchi method. Polymer Engineering \& Science, 41(5), 703-710.

[10] Mitra, A. C., Jawarka, M., Sonic, T., Kiranchand, G. R. (2016). Optimization of the operating parameters based on Taguchi method for robust suspension design. Procedia Engineering, 144, 77-84. 